\title{
VORSCHAU $12>$
}

\section{ENTWICKLUNG}

Analysemethoden für den Anteil recycelter Kunststoffe in Automobilteilen

Flachbahnprüfstand zur Ermittlung von $\mathrm{CO}_{2}$-Potenzialen

\section{Objektivierung der Fahrbarkeit beim automatisierten Fahren}

\author{
Regelbare Ölpumpe zur Radsatz- \\ schmierung in Getrieben
}

Konforme und integrierte 3D-Antennensysteme für das Connected Car

\section{Entwicklung eines}

Hochvolt-Kühlmittel-Heizgeräts

Report: Die Elektromobilität und die Folgen für den Standort Deutschland

\section{FORSCHUNG}

Simulation der Zuverlässigkeit von Fahrzeugfunktionen am Beispiel Fahrkomfort

TITELTHEMA

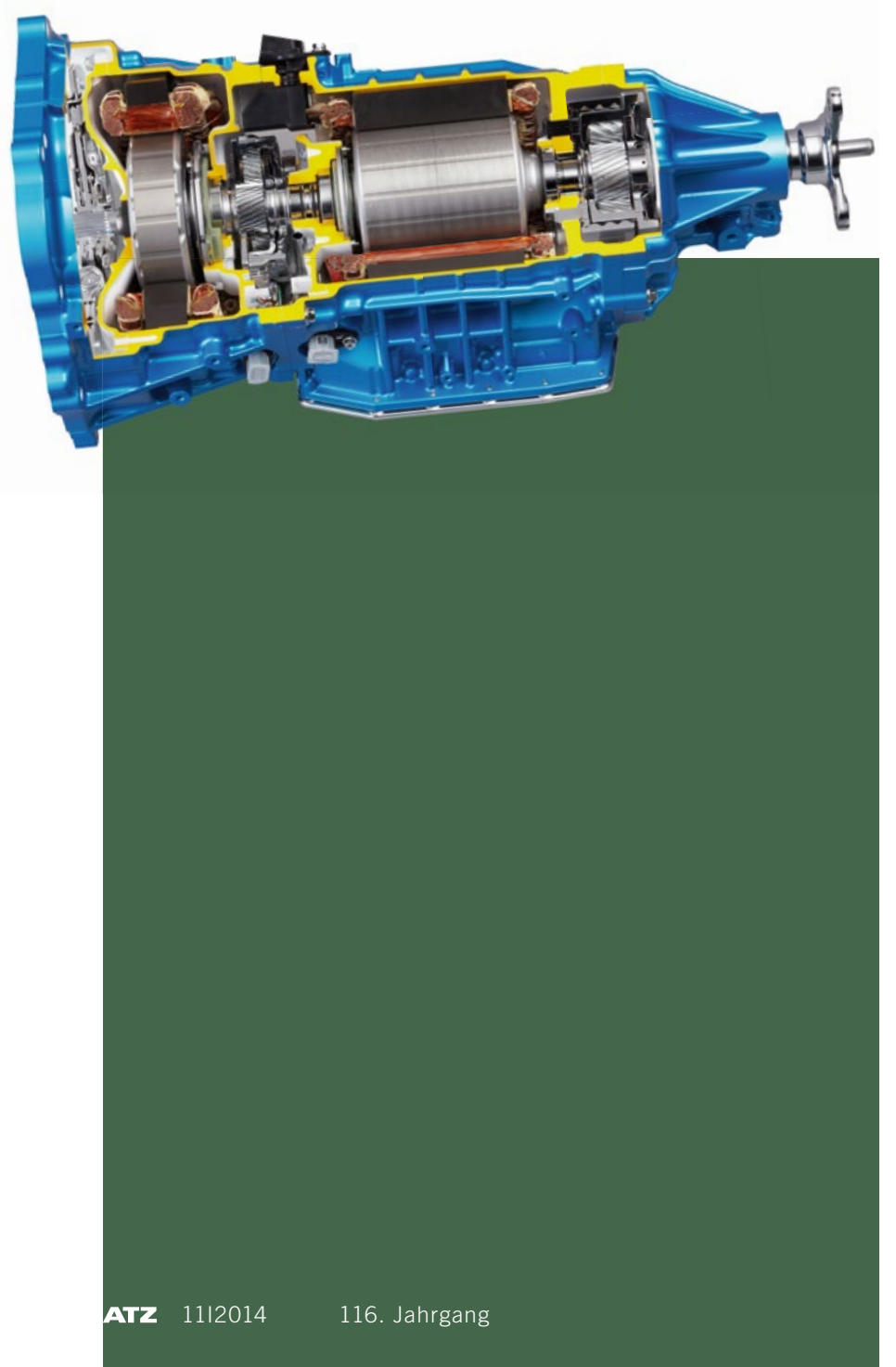

\section{HERAUSFORDERUNG GETRIEBEENTWICKLUNG}

Die Getriebetechnik für Pkw steht nicht still. Hybridisierung und Hochintegration bei gleichzeitig steigender Effizienz sind Aufgaben, die Ingenieure heute für morgige Fahrzeuge lösen müssen. Passend zum CTI-Getriebesymposium in Berlin am 9. und 10. Dezember stellt die ATZ im Titelthema der Dezemberausgabe neue Konzepte von zwei Zulieferern vor.

Getrag untersucht den Vergleich der Eigenschaften eines 48-V-Hybridgetriebes mit per Riemen angebundener E-Maschine zu einem hybridisierten Doppelkupplungsgetriebe mit integrierter E-Maschine. Dieses Torque-Split-Hybridgetriebe 7HDT300 zeichnet sich durch hohe Skalierbarkeit sowie einen kennfeldoptimierten Betrieb aus.

Plug-in-Hybridsysteme auf der Basis des Parallelhybridkonzepts können bei Komfort, Dynamik und Effizienz neue Maßstäbe setzen. Für diese Anwendung hat ZF sowohl ein hochintegriertes Gesamtsystem als auch ein Hybridmodul zur Realisierung von Plug-in-Hybridfahrzeugen zur Serienreife entwickelt.

Mit Prof. Dr.-Ing. Stephan Rinderknecht, dem Institutsleiter des IMS der TU Darmstadt, diskutiert die ATZ die Vorteile von nassen und trockenen Kupplungen in Doppelkupplungsgetrieben und warum ganzheitliche Car-in-the-Loop-Prüfstände für die Getriebeentwicklung notwendig werden. 